\title{
Food Beliefs and Practices among Sri Lankans. 3. Estate Sector
}

\author{
Chandrani LiYanage and T. W. Wikramanayake \\ Faculty of Medicine, Ruhuna University College, Galle \\ (Date of receipt: 13 June 1983) \\ (Date of acceptance: 08 June 1984)
}

\begin{abstract}
Food avoidances during pregnancy and lactation and weaning practices among 300 mothers in estates in the Districts of Kandy and Nuwara Eliya have been studied. Although several comparisons are seen between practices among these mothers and those in South India, food taboos have less influence on the diet among Sri Lankan estate workers than among those in South India, probably due to the greater accessability to clinics and hospitals on estates. The reasons given for avoidances are the "hot-cold" nature of food, their possible effect on the course of the pregnancy, on discharge of lochia after delivery and the effects on quantity and quality of milk secreted. Most mothers start breast-feeding within 48 hours after delivery and about one-third continue partial breast-feeding beyond the second year. Bread and biscuits are the first solid foods to be fed, most infants being fed rice towards the end of the first year.
\end{abstract}

\section{Introduction}

Two previous reports dealt with temporary food avoidances and weaning practices among Sinhala Buddhist women. ${ }^{5},{ }^{8}$ During a study of socio-cultural malnutrition in the estate sector, food avoidances during pregnancy and lactation and weaning practices among a predominantly Tamil Hindu population were ennumerated. The results obtained are compared with those reported earlier and with reports of such avoidances and practices in South India from where the estate population originated.

\section{Methods}

Four estates in the Kandy Superintendent of Health Services Division were selected, two in Kandy District and two in Nuwara Eliya District. Seventy-five families were selected from each estate by random sampling. Nearly $93 \%$ of the population studied were Tamil $92.1 \%$, Hindu. The Sinhalese formed $7 \%$ and there were $6.5 \%$ Buddhists and $1.4 \%$ Christians.

By means of a questionnaire, information was collected from the 300 mothers on food habits, prejudices and practices and the history of feeding the child from birth to pre-school age. The questionnaire was first tested on an estate near Kandy, to ensure clarity and non-ambiguity of the questions, and to orient two Tamil female undergraduates who assisted as interviewers. A satisfactory relationship was first established with the mothers in maternity homes, dispensaries and creches. Once rapport was established, interviews were conducted in the privacy of their homes. 


\section{Results}

\subsection{Food avoidance during pregnancy and lactation}

Table 1 lists the foods most frequently avoided by women during pregnancy and lactation.

TABLE 1. Frequently avoided foods during Pregnancy and Lactation and the percentage of women avoiding them

\begin{tabular}{lcc}
\hline Foods avoided & Pregnancy & Lactation \\
\hline Heaty foods & 8.0 & 10.0 \\
Cooling foods & 6.0 & 10.0 \\
Rice, raw & 6.0 & - \\
Rice, parboiled & 4.0 & 1.0 \\
Yams & - & 6.0 \\
Jak, bread fruit & - & 14.3 \\
Leafy vegetables & 7.0 & 8.0 \\
Tomato.. & 4.0 & 7.0 \\
Milk, (Cow, Goat) & - & 6.0 \\
Curd & 2.6 & 8.0 \\
Egg & 4.6 & 44.0 \\
Fish & 2.6 & 48.0 \\
Small fish & 4.0 & 40.0 \\
Dried fish & 1.0 & 13.0 \\
Papaw & 11.3 & 24.0 \\
Pineapple & 54.0 & 12.0 \\
Mango & 8.0 & \\
\hline
\end{tabular}

The reasons for such avoidance are many and varied, the most commonly mentioned being that a particular food is either "heaty" or "cooling". Among "heaty" foods listed by the women are fish, chicken, sardines, egg and meats, country rice (under-milled), white rice, roti made of wheat or rice flour, yams, jak fruit, beans, dhals, knolkol, raw papaw, brinjals, carrots, tomatoes, green leafy vegetables, colocasia and manioc leaves, and foods fried in oil. During pregnancy, these are believed to be gas-forming, produce vomiting, stomach-ache, pain in limbs, irritation and redness in eyes, diarrhoea, difficulty in urination, excessive sweating, giddiness, burning sensation in breasts and stomach, ulceration in mouth and tongue, splitting of skin at the heels, fissures in tongue, swelling over limbs, lips and eyelids in the mother, and diarrhoea and stomach-ache in the newborn. Many admitted they avoided these "heaty" foods because it was the custom.

During lactation, heaty foods are believed to reduce the secretion of milk, and cause diarrhoea in infant, inflammation in the throat of mother and infant, in addition to producing other effects listed earlier. 
Among "cooling" foods are pumpkin, banana, ripe papaw, avocado, "undu" (Phaseolus mungo), okra, beetroot, agathi, salad leaves, leeks and mutton. During pregnancy cooling foods are believed to produce chills, fever, diarrhoea, severe uterine bleeding, fits, gastro-intestinal disturbances in the newborn, asthma and chest pain in the mother. Some avoided these foods following advice of the motherin-law. During lactation such foods are believed to produce colds, fits, chills, and fever, even diarrhoea in infant, asthma and chest pain in mother and lowered secretion of milk.

Apart from being either "heaty" or "cooling" certain specific reasons were given for avoiding some foods.

Raw rice eaten during pregnancy was believed to result in the new-born having protruding eyes. During lactation it would be too heaty for the infant. Parboiled rice was thought by some to be difficult to digest, not nutritious, and could lower milk secretion. Yams are not nutritious, too "heavy", could produce vomiting in mother and infant, and is generally forbidden by the elders in the community. Jak and bread fruit eaten during lactation could be too heaty and heavy for the infant, produce diarrhoea in infant, pain in lower abdomen of mother and reduce milk flow.

Curd is avoided during pregnancy because it is considered too acidic, and may lead to inflammation in stomach and oesophagus. Some considered it sinful to eat curd during this period. During lactation, curd is believed to make breast milk sour and produce vomiting, and to produce diarrhoea in mother and throat pain in infant.

Green leafy vegetables are believed to be difficult to digest during pregnancy; they may get stuck on the intestinal wall, and produce diarrhoea, fever, vomiting, headache. Eaten during lactation they are believed to reduce milk secretion, discolour breast-milk and in the infant develop gastro-intestinal disorders.

Tomato, eaten during pregnancy, is said to increase uterine bleeding and in the new-born produce irritation of throat, dry skin and mandama (marasmus). During lactation it will produce vomiting in both mother and infant and skin rashes on infant. Elders strongly advise against eating it.

Most women avoid fish during lactation. It is believed to give a bad odour to the lochia and urine, bad odour to breast milk, and produce mandama in infant. Bones of small fish cannot be digested. Fish eaten during lactation could produce irregular uterine bleeding. The few who avoided eggs thought egg gives a bad odour to sweat and lochia, is indigestible, produces vomiting and headache in the mother. The infant could develop boils on the skin and vomiting. 
A small percentage of women avoided milk during lactation. Milk was consumed during pregnancy in spite of the belief among elders that milk could produce irritation in body and excessive uterine bleeding. When taken during lactation milk is said to produce dry skin in infant and make it prone to infectious diseases, even produce asthma and fits in infant. Some believed that milk secretion is reduced when cows' or goats' milk is consumed.

Among fruits pineapple was the most avoided. When eaten during pregnancy it is believed to produce severe bleeding, even abortion, and skin rashes on mother and new-born. When a lactating woman eats pineapple her milk is said to become sour, making the infant vomit it. Women are advised against eating papaw during pregnancy as it might result in abortion, or swelling of the limbs, headache, stomach-ache, even fever. It is avoided till about 7 months after delivery as it is thought to make the milk sour and produce diarrhoea and vomiting in the infant. Mango could also produce bleeding, sometimes abortion, and result in a marasmic infant. Eaten during lactation, it is said to make breast milk sour and discoloured, produce boils on both mother and child, and even result in colds and fever in the infant.

\subsection{Breast feeding and weaning}

By breast feeding is meant "sucking at the breast", whether it be frequent or limited to two or three times a day. The word "wean" is used to mean "to teach the child to feed otherwise than at the breast", a process that might take a few weeks or several months. Table 2 indicated that about $75 \%$ of the mothers commence breast-feeding within 48 hours after delivery. Less than $18 \%$ started nursing within a few hours after delivery.

TABle 2. Commencement of Breast-feeding

\begin{tabular}{lllllrl}
\hline Plantation & $A$ & $B$ & $C$ & $D$ & \multicolumn{2}{c}{ All } \\
\hline Number of mothers & 75 & 75 & 75 & 75 & \multicolumn{2}{l}{300} \\
\hline & & & & & No. & $\%$ \\
Few hours post partum & 22 & 05 & 11 & 15 & 53 & 17.7 \\
One day & 15 & 13 & 12 & 17 & 57 & 19.0 \\
Two days & 26 & 49 & 17 & 23 & 115 & 38.3 \\
Three days & 09 & 07 & 30 & 12 & 58 & 19.3 \\
Four days & 01 & 00 & 03 & 05 & 09 & 3.0 \\
Five days & 02 & 01 & 12 & 03 & 08 & 2.7 \\
\hline
\end{tabular}

The beliefs held regarding the feeding of colostrum are : difficult to digest the yellow milk, it is impure, infants will develop diarrhoea, it is not palatable, the infant rejects it due to its sour taste, it is not necessary for the child, it is mixed with waste matter and is therefore not good for the infant. Some said it would be a strain on the mother to feed immediately after delivery. Many thought that boiled and cooled water with a little castor oil would suffice and that milk is not needed till the third day post-partum. 
The duration of breast-feeding was ascertained by inquiring as to how long the youngest child in the family had been nursed. The pattern appears to be uniform in all four estates studied. Only about $10 \%$ stop nursing by the end of the 6th month, nearly $85 \%$ continue to breast-feed partially for one year. One-third of the mothers continue for 2 years and another third for more than 2 years.

TABLE 3. Duration of Breast-feeding of the Youngest Child

\begin{tabular}{lcccccc}
\hline Plantation & $A$ & $B$ & $C$ & $D$ & \multicolumn{2}{c}{ All } \\
\hline Number of mothers & 75 & 75 & 75 & 75 & \multicolumn{2}{c}{300} \\
& & & & & No. & $\%$ \\
\hline 3 months & 3 & 2 & 2 & 5 & 12 & 4.0 \\
6 month s & 6 & 5 & 2 & 5 & 18 & 6.1 \\
9 months & 4 & 2 & 0 & 9 & 15 & 5.1 \\
12 months & 14 & 19 & 10 & 14 & 57 & 19.2 \\
1 to 2 yrs. & 25 & 23 & 25 & 24 & 97 & 32.8 \\
2 yrs. & 22 & 23 & 34 & 18 & 97 & 32.8 \\
\hline
\end{tabular}

Four mothers had not breast-fed the youngest child.

Table 4 lists the food items frequently given to children during the period of weaning.

TABLE 4. Food items frequently given to children below 3 years and percentage of children receiving these items at different ages

\begin{tabular}{|c|c|c|c|c|c|c|}
\hline \multirow[b]{2}{*}{ Food Item } & \multicolumn{6}{|c|}{ Percentage of children getting the item at different ages } \\
\hline & $0-3 m$ & $4-6 m$ & $7-12 m$ & $13-18 m$ & $19-24 m$ & $24-36 m$ \\
\hline Cows' milk, fresh & 18.3 & 30.6 & 36.6 & 39.9 & 41.2 & 42.2 \\
\hline Milk powder & 44.0 & 56.6 & 62.2 & 64.5 & 66.8 & 68.1 \\
\hline Rice cunjee & 1.6 & 7.6 & 16.6 & 24.2 & 26.5 & 28.1 \\
\hline Kola kande (leaf cungee) & 0.3 & 2.3 & 6.6 & 11.9 & 14.5 & 15.5 \\
\hline Bread, biscuits & 03 & 8.6 & 31.6 & 70.5 & 86.7 & 100.0 \\
\hline Coriander water & 28.6 & 47.9 & 55.9 & 64.1 & 65.7 & 67.3 \\
\hline Pulses & - & 3.6 & 21.9 & 67.9 & 87.4 & 100.0 \\
\hline Yams, potatoes & - & 3.6 & 12.9 & 63.9 & 85.2 & 99.8 \\
\hline Rice and curry & - & 2.3 & 21.9 & 78.8 & 93.8 & 100.0 \\
\hline Boiled vegetables and soups & - & 1.3 & 11.6 & 33.5 & 42.5 & 46.5 \\
\hline Egg & - & 2.0 & 17.3 & 55.5 & 70.8 & 82.4 \\
\hline Fish & - & - & 8.6 & 46.2 & 65.2 & 83.2 \\
\hline Meat & - & - & 5.3 & 43.3 & 61.3 & 79.3 \\
\hline Small fish & - & - & 6.0 & 35.0 & 47.0 & 59.0 \\
\hline Papaw & 1.0 & 8.3 & 26.9 & 61.8 & 81.8 & 98.4 \\
\hline Pineapple & - & 1.3 & 11.9 & 31.1 & 49.4 & 74.0 \\
\hline Mango & 0.3 & 6.3 & 22.3 & 59.2 & 73.8 & 79.8 \\
\hline Banana & - & 3.3 & 21.6 & 56.9 & 74.2 & 91.8 \\
\hline
\end{tabular}


Milk powder feeding is introduced after 3 months in nearly half the households and in more than $60 \%$ by the end of the first year. It is used as a supplement rather than as a substitute, as nearly one-third of the children continue to be partially breast-fed at the end of 2 years. Sweetened coriander water is the next most popular weaning food. However, even by the end of the third year neither milk powder nor coriander water had been given to about one-third of the children. Rice cunjee is given by very few mothers. It is considrered a food for the sick, not for healthy babies. "Kola Kande" is even less popular. Bread, biscuits and rice cunjee are the first solid foods to be introduced, by the 6 th month, and bread and biscuits continue to gain in popularity as the child grows older. Rice and curry were given to a small proportion of the children before the 6th month, and only about $22 \%$ of children had received such a meal before the end of the first year. Most children shared the family's rice and curry meals when they were 12 to 18 months old. In contrast to Sinhala children, less than $15 \%$ were fed boiled potatoes or yams before their first birthday. When these are fed, they are usually in the form of curries. Fruits such as mango and papaw are introduced very early and about one-quarter of the children are fed fruit regularly by the end of the first year. Among foods of animal origin, other than milk, egg is the most popular. After the first birthday nearly half the children are fed either egg, meat or fish.

\section{Discussion}

Table 5 lists some food items avoided during pregnancy and lactation by women in Tamilnad.3,4 A comparison with the data in Table 1 shows that food taboos influence the diet of the Sri Lankan estate sector less that they do in South India from where they came, probably due to the fact that the estate population have for generations been exposed to clinics and hospitals in the estate. Only a few of them avoid milk during lactation, and that too mainly in the first month, as long as the flow of lochia continues. Non-vegetarian foods, other than milk, are avoided by both groups and for similar reasons. However, the fear that eggs, milk and meat eaten during pregnancy would result in too big a baby, is not as evident in Sri Lanka as in South India. In Tamilnad, although fish and small fish are taboo for several months, dried fish is eaten from the third day after delivery, in the belief that it would increase milk flow. ${ }^{4}$ In the present study, too, the women said they would eat it were it available more freely. In both groups fruits constitute a major source of danger after delivery. In contrast to temporary abstentions from other foods, where the number of women avoiding them decreases with the period of lactation, several women do not eat fruits for the whole of the lactation period. This is done almost exclusively in the interest of the child. Avoidance of papaw is linked to female discharge during pregnancy and lactation, although the taboo is not as strong in Sri Lanka as in South India. Among both groups pineapple is avoided, more during pregnancy than during lactation, due to its presumed power to induce 


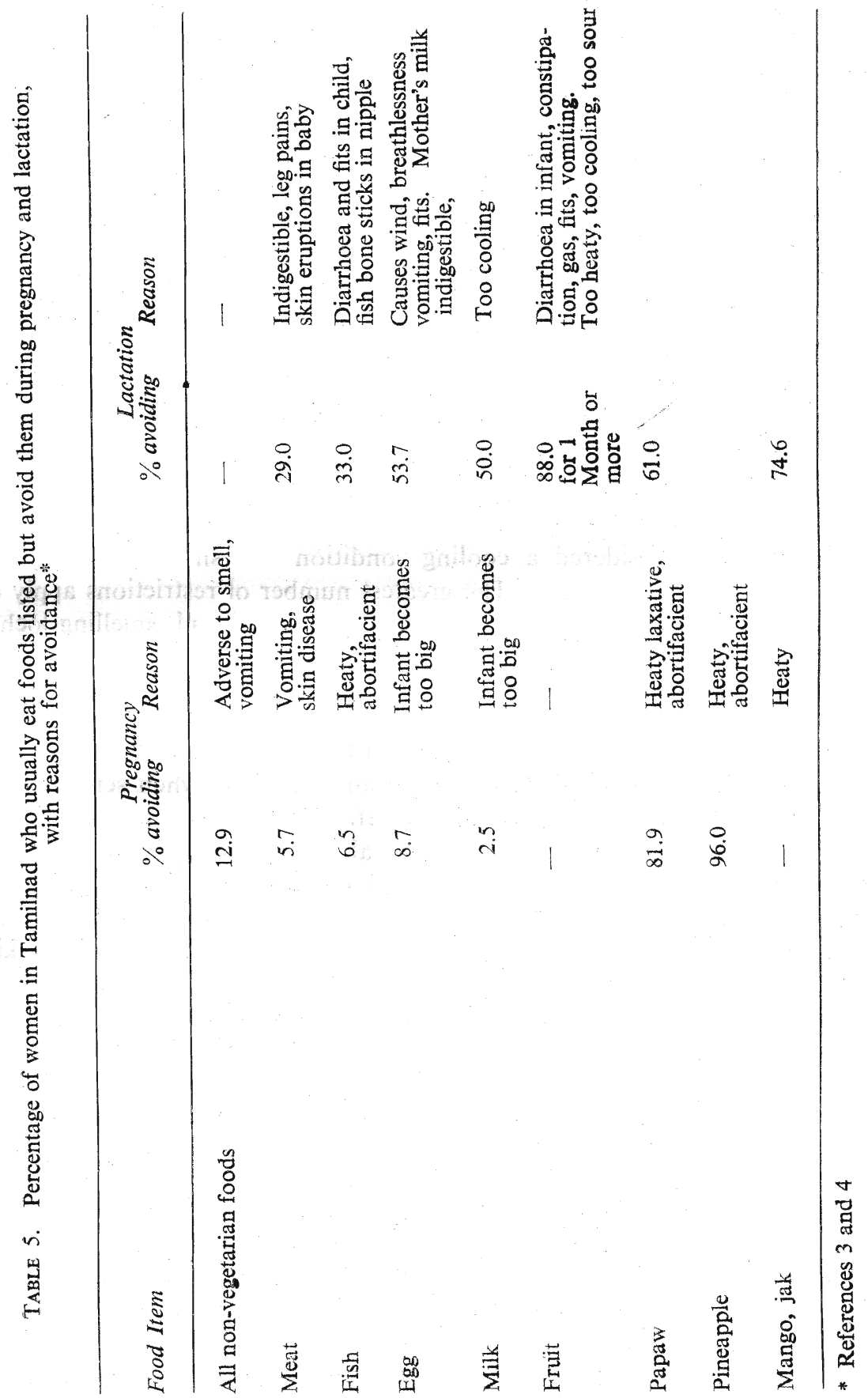


abortion. This fear occurs beyond the borders on India and Sri Lanka among the Malays and Chinese in Malaysia, ${ }^{4,9}$ among Chinese in Singapore, ${ }^{4}$ in Indonesia, ${ }^{4}$ and in Central America. ${ }^{\circ}$

After delivery vegetables are avoided mainly because they are "cooling". In Tamilnad, $65.9 \%$ avoided such vegetables, at least for a month. Ash pumpkin (Cucurbita maxima), the most feared for this effect, is also forbidden to Sinhala mothers. ${ }^{6}$

Among Tamils in the estate sector and in Tamilnadu, and among Sinhalese, ${ }^{7,8}$ pregnancy is considered a heaty condition. Therefore, a pregnant woman is advised to avoid heaty foods as well as those that are very cooling. Other foods are avoided because they are gas forming, cause wind and make the woman very uncomfortable. The third category include those that are considered abortifacients.

Delivery is a cooling process and the woman is given a "rasam" (a spiced broth containing garlic, pepper, ginger and onions), and black coffee.

Lactation is considered a cooling condition and she avoids very cooling foods as well as very heaty ones. The greatest number of restrictions apply during the first few months of lactation, in an attempt to avoid foul smelling lochia and to stop the flow of lochia. Also avoided are foods that are believed to reduce milk secretion or alter the colour or consistency of the milk.

It is difficult, and probably unwise, to attempt to change drastically customs and habits that have been hallowed by tradition, especially when scientific reasons are lacking for discouraging a particular belief. For instance, the fear that pineapple acts as an abortifacient is almost universal. That pineapple does not produce this effect has not been proved. That papaw could discolour the milk has to be admitted. Evidence, both published ${ }^{2}$ and unpublished, indicates that eating one or two papaws daily for about 5 days produces yellow discolouration of skin and conjunctiva due to carotenaemia. In a health education programme it should be pointed out that one serving of papaw daily would be harmless. Women could also be told that the pigment in the milk, far from being harmful to the infant, would protect the child from developing eye disease. The eating of dried fish should be encouraged, both during lactation as well as during pregnancy, and more of it should be made available at the co-operative store at a subsidised rate.

Most women avoid feeding colostrum to the new-born (Table 1 and refs. $\left.{ }^{2}, 7,8\right)$. Water mixed with a few drops of castor oil and some powdered sucrose is given to "cleanse the intestine" and this is followed by sweetened coriander water. Estate women, like the Sinhalese, introduce milk powder early, in contrast to their counterparts in South India, although about one-third might continue feeding breast-milk as the only milk food throughout the first year. However, due to the 
high cost of milk powder the milk is likely to be fed in high dilution. The dangers of bottle-feeding should be explained as well as the need to boil the utensils and the water used. An effort should be made to encourage breast-feeding very early after delivery.

Early introduction of biscuits and rice cunjee could be encouraged, to ensure adequate energy intake. Addition of pulses, well-boiled and mashed, to the rice, could be encouraged from the sixth month onward, once solids are accepted by the infant, and an attempt made to ensure that all children are fed rice by the end of the first year.

\section{Acknowledgements}

Mrs. Chandra Liyanage received a grant from the Natural Resources, Energy and Science Authority of Sri Lanka.

\section{References}

1. De gonzales, N. L. S. (1963). Tropical Geographical Medicine, 15, 427.

2. De Silva, W. A. S. \& Boralessa, H. (1971). Ceylon M.J. 16, 230.

3. Ferro-Luzzi, G. Eichinger, (1973). Ecology of Fd. and Nutr. 2, 259.

4. Ferro-Luzzi, G. Eichinger, (1974). Ecology of Fd. and Nutr. 3, 715.

5. Karaliedde Srikanthi, Chandrani Weerasinghe \& Wikramanayake, T. W. (1982) J. Natn. Sci. Coun. Sri Lanka, 10, (2).

6. Raghavan, M. D. (1951). Ethnological Survey of Ceylon II. Spoilia Zeylanica 26, 224.

7. Schuttelaar, Marcel \& Edith Van Walsum (1979). Food Habits and Nutrition of Children and Women. A field study in two Sri Lankan Communities, Report of a field study for the part fulfilment of post-graduate study in Human Nutrition at the Agricultural University, Wageningen, the Netherlands.

8. Weerasinghe, Chandrani, Srikanthi Karaliedde \& Wikramanayake, T W. (1982). J. Natn. Sci. Coun. Sri Lanka, 10, 159.

9. Wilson, Christine (1973). Ecology of Fd. and Nutr. 2, 267. 